\title{
Chemical profiling, biostatic and biocidal dynamics of Origanum vulgare L. essential oil
}

\author{
Sahar Fikry ${ }^{1}$, Noha Khali $2^{*}$ (II) and Osama Salama ${ }^{2}$
}

\begin{abstract}
Origanum vulgare L. (Lamiaceae) is a widespread flavoring culinary and medicinal herb. The present study aimed at investigating the antimicrobial activity of Origanum vulgare (OV) essential oil (EO) through illustrating its biostatic, biocidal and the dynamics of the biocidal activity against 11 different microorganisms. GC/MS of OV EO allowed the identification of 32 compounds representing $99.94 \%$ of the oil. The two major identified compounds were terpinen4-ol (38.35\%) and trans-sabinene hydrate (10.06\%). Different methods were employed to illustrate the biostatic activity of OV EO. Results of the biostatic studies on OV EO using agar and broth dilution methods showed that Staphylococcus aureus (S. aureus) was the most sensitive organism; with a Minimum inhibitor concentration (MIC) $1.18 \mathrm{mg} / \mathrm{ml}$. Agar diffusion method showed that the highest activity was observed against Bordetella bronchiseptica (Br. bronchiseptica), Saccharomyces cerevisiae (S. cerevisiae), Bacillus subtilis (B. subtilus) and Staphylococcus epidermidis (S. epidermidis) with inhibition zones $38 \pm 1.5,29.5 \pm 0.8,26.9 \pm 0.9$ and $26.9 \pm 1.1 \mathrm{~mm}$, respectively. Studying the dynamics of $1 \% \mathrm{~V} / \mathrm{V}$ OV essential oil emulsion over a period of $6 \mathrm{~h}$ revealed that Escherichia coli (E. coli), B. subtilis, S. epidermidis and S. cerevisiae had the fastest response. Also increasing concentrations of OV oil emulsion increased the rate of cell killing and the duration of growth lag phase increased correspondingly. These data indicated that OV EO produces a concentration and time-dependent antimicrobial activity.
\end{abstract}

Keywords: Origanum vulgare, Essential oil, GC/MS, Terpinen-4-ol, Biostatic, Biocidal dynamics

\section{Introduction}

Some medicinal and aromatic plants (MAPs) are a rich source of essential oils, which have proven to possess a wide variety of biological activities such as antimicrobial, anti-inflammatory, antiseptic, anticancer, analgesic and sedative effects (Bhalla et al. 2013; Dhifi et al. 2016). Origanum vulgare L. (OV), which is also known as oregano or marjoram is a widespread flavoring culinary herb belonging to family Lamiaceae (Kokkini et al. 2003). Traditionally, the plant has been employed as a remedy for different ailments like gastrointestinal disorders, colds, whooping and convulsive coughs, menstrual problems, headaches, depression and pruritis (Fleisher and Sneer 1982; Krishnakumar and Potty 2012). The plant's essential oil and different extracts

\footnotetext{
*Correspondence: noha.hassan@fue.edu.eg

${ }^{2}$ Faculty of Pharmaceutical Sciences and Pharmaceutical Industries,

Future University in Egypt, Cairo 11835, Egypt

Full list of author information is available at the end of the article
}

have been reported as antioxidant, antimicrobial, antiinflammatory as well as hypolipidemic (Bhat et al. 2018; Elshafie et al. 2017; Leyva-López et al. 2017; Milos et al. 2000; Morshedloo et al. 2018; Soliman et al. 2016). The essential oil composition varied widely according to the geographical area and growth conditions (Gong et al. 2014; Hernández-Hernández et al. 2014; Morshedloo et al. 2017). Studies show that OV EO mostly contains phenolic compounds, mono-and sesquiterpene hydrocarbons, as well as their oxygenated derivatives. Major identified compounds in Chinese OV EO were thymol (42.9\%) and $p$-cymen-2-ol (37.5\%), while OV EO collected in Pakistan contained mainly $\beta$-citronellol (78.7\%) and citronellol acetate (5.9\%) (Gong et al. 2014). Essential oil of Saudi Arabia OV contained mainly carvacrol (70.2\%) and $\gamma$-terpinene (5.6\%) (Khan et al. 2018). On the other hand, Mexican OV EO had major its major compounds thymol (66.3\%) and $\gamma$-terpinene (9.6\%) (Hernández-Hernández et al. 2014) and the Brazilian one contained thymol (21.9\%) and carvacrol 
(4.7\%) as major constituents (Pradebon Brondani et al. 2018). OV cultivated in Spain contained in its essential oil cis-sabinene hydrate (37\%) and terpinene-4-acetate (16.2\%). This compositional variation may be attributed to difference in growth conditions, origin of plant collection, stage of plant maturity, physiological modifications in response to various environmental factors and stresses, harvesting time, drying methods, method of essential oil isolation or even the solvents used for the GC/MS analysis (Arranz et al. 2015; Moghaddam and Mehdizadeh 2017).

Recently, there has been a growing interest in the use of crude essential oils or their pure isolated compounds in the food and pharmaceutical industries, either as preservatives or antimicrobial agents (Herman et al. 2013; Prakash et al. 2012). They are being relied on as natural alternatives rather than the use of synthetic chemical agents; which cause multidrug resistance and several side effects. This is due to their constituents of bioactive compounds which possess both antioxidant and antimicrobial properties. Essential oils of different Origanum species have demonstrated good antimicrobial effects against various bacteria including S. aureus, Salmonella spp., Pseudomonas and E. coli, and fungi including Candida albicans and Aspergillus spp. (Bhat et al. 2018; Carneiro de Barros et al. 2009; Chaves-Lopez et al. 2012; Coccimiglio et al. 2016; de Barros et al. 2012; Kacaniova et al. 2017). The oil is known to be rich in compounds with strong antimicrobial activity like thymol, carvacrol, $\gamma$-terpinene, as well as cis- and trans-sabinene hydrate (Didry et al. 1993; Lee et al. 2013; Magi et al. 2015; Sharifi-Rad et al. 2018). Standardized reliable methods are essential for the elucidation of the antimicrobial activity and therapeutic potential of essential oils.

The present study aimed at investigating the in vitro antimicrobial activity of OV EO through illustrating its biostatic, biocidal and the dynamics of the biocidal activity against 11 different American Type Culture Collection (ATCC) microbial strains microorganisms. This was in addition to chemical profiling of the essential oil using GC/MS technique in order to relate the antimicrobial activity to the essential oil composition.

\section{Materials and methods}

Plant material

Origanum vulgare (OV) plants were collected from the medicinal farm of Arab Company for Pharmaceuticals and Medicinal plants (Mepaco. Medifood, Egypt). Plants identity was authenticated by Prof. Mohamed El-Gebaly, professor of plant taxonomy, at the Department of Botany of the National Research Center in Egypt.

\section{Extraction of OV EO}

Dried aerial parts of $O$. vulgare were subjected to hydro-distillation using a Clevenger-type apparatus, for $4 \mathrm{~h}$. The obtained essential oil was dried over anhydrous sodium sulfate. The oil was kept refrigerated in a sealed amber vial till use.

\section{Identification of OV EO compounds using GC/MS}

An Agilent 7890A gas chromatograph (Agilent Technologies, Palo Alto, CA, USA) equipped with a RTX$5 \mathrm{MS}$ capillary column $(30 \mathrm{~m} \times 0.32 \mathrm{~mm}$, film thickness $0.25 \mu \mathrm{m})$ was used for the GC-MS analysis of OV EO. The apparatus was coupled to an Agilent 5975C (Agilent Technologies, Palo Alto, CA, USA) mass selective detector. Initial oven temperature was kept at $40{ }^{\circ} \mathrm{C}$ for $2 \mathrm{~min}$. Temperature was then raised at a rate of $5{ }^{\circ} \mathrm{C} / \mathrm{min}$ till reaching $210{ }^{\circ} \mathrm{C}$. Temperatures of both the injector and detector were adjusted at 290 and $300{ }^{\circ} \mathrm{C}$, respectively. Helium was used as a carrier gas with a flow rate of $2 \mathrm{ml} /$ min. OV oil sample $(0.1 \mu \mathrm{l})$ was injected manually in the split mode. Mass spectra were recorded in EI mode and $35-500 \mathrm{~m} / \mathrm{z}$ range with ionization voltage, $70 \mathrm{eV}$. Ion source temperature was set at $230{ }^{\circ} \mathrm{C}$. Kovat's index was calculated for all compounds using a homologous series of $n$-alkanes $\left(\mathrm{C}_{5}-\mathrm{C}_{24}\right)$ using the same operating conditions. Identification of different oil compounds was based on comparison of the obtained spectra with those available from MS libraries (Wiley) and by comparison of their experimentally determined Kovat's index (KI) with those reported in the literature (Adams 2007). Peak areas were used for quantization of relative percentages of identified compounds.

\section{Antimicrobial studies \\ Preparation of sterile OVEO}

OV EO emulsion $(10 \% \mathrm{v} / \mathrm{v})$ was prepared by thoroughly triturating ten volumes of the oil with one volume of Tween 20 (10 ml oil $+1 \mathrm{ml}$ Tween 20$)$. The total volume was completed to 100 with distilled water. The resultant emulsion was sterilized by filtration though a $0.45 \mu \mathrm{m}$ membrane filter (Millipore, USA) and refrigerated in a sealed amber vial till use.

\section{Source of microorganisms}

The antimicrobial activity of OV EO was evaluated using laboratory reference strains ATCC for bacteria and fungi; which were purchased from IMTECH, Chandigarh, India. The tested microorganisms are listed in Table 3.

\section{Culture media}

Tryptic Soybean-Casein Digest Broth (TSB), Tryptic Soybean-Casein Digest Agar (TSA), Sabouraud 
Dextrose Broth (SDB) and Sabouraud were used as culture media and were sterilized according to the directions of the manufacturer (Sigma, USA).

\section{Preparation of microbial inocula}

- Vegetative bacterial strains: were grown in TSB at $37{ }^{\circ} \mathrm{C}$ for $18 \mathrm{~h}$ and diluted 1:100 with sterile TSB before use.

- Yeast strains: were grown in SDB ate $25^{\circ} \mathrm{C}$ for $48 \mathrm{~h}$ and used undiluted.

- Bacterial spores: B. subtilis culture was heavily streaked onto TSA plate and incubated ate $37^{\circ} \mathrm{C}$ for 5 days. The bacterial growth was scrapped off using sterile saline, vortexed and centrifuged for $5 \mathrm{~min}$ at $300 \mathrm{rpm}$. The pellet was suspended in sterile saline, vortexed and re-centrifuged. The resultant washed pellet was re-suspended in sterile saline and heated for $30 \mathrm{~min}$ in a water-bath at $80{ }^{\circ} \mathrm{C}$ to kill any vegetative cells. The resultant spore suspension was used as inoculum to study the dynamics of the biocidal activity of OV EO.

- Fungal spores: A. niger culture was grown as heavy streaks on SDA plate and incubated at $25{ }^{\circ} \mathrm{C}$ for 5 days. The developed spores were recovered using sterile saline containing $0.005 \% \mathrm{v} / \mathrm{v}$ Tween 20 . The resultant spore suspension was vortexed and centrifuged for $5 \mathrm{~min}$ at $3000 \mathrm{rpm}$. The spore deposit was washed by dispersion in sterile saline-Tween, vortexed and re-centrifuged. The recovered washed spores were suspended in sterile saline-Tween and used as inoculum to study the biostatic activity of OV essential oil.

\section{Biostatic activity of OV EO Agar dilution method}

Ten $\mathrm{ml}$ of stock OV EO emulsion $(10 \% \mathrm{v} / \mathrm{v})$ were twofold serially diluted with distilled water. Each of the oil dilution was thoroughly mixed with an equal volume of double-strength sterile molten TSA or SDA maintained at $50{ }^{\circ} \mathrm{C}$ in a water bath. Portions of the TSA-oil or SDAoil were poured onto sterile petri dishes, allowed to solidify and left to dry at room temperature for $30 \mathrm{~min}$. Ten microliter (ca $10^{5} \mathrm{CFU} / \mathrm{ml}$ ) aliquots of each of the prepared microbial inocula were transferred into the surface of the TSA-oil or SDA-oil plates as indicated. Inoculated TSA plates were than incubated for $24 \mathrm{~h}$ at $37^{\circ} \mathrm{C}$ while the SDA plates were kept for $2-5$ days at $25^{\circ} \mathrm{C}$. MIC of the oil was determined for each organism by visual inspection of the plates. MIC was considered as the lowest oil concentration giving no visible microbial growth;
1-2 colonies were neglected. Average of 3 results was recorded (Griffin et al. 2000).

\section{Broth dilution method}

Broth dilution method was performed according to Clinical and Laboratory Standards Institute (CLSI 2012). Ten $\mathrm{ml}$ of stock OV EO emulsion $(10 \% \mathrm{v} / \mathrm{v})$ were twofold serially diluted with sterile distilled water. Each oil dilution was mixed with equal volume of double strength sterile TSB or SDB and inoculated with $100 \mu \mathrm{l} / 5 \mathrm{ml}$ mixture of the test inoculum followed by thorough mixing. Cultures were adjusted to $0.5 \mathrm{McF}$ arland standard which contains approximately 1 to $2 \times 10^{8} \mathrm{CFU} / \mathrm{ml}$ with tested bacterial strains, then dilute the 0.5 McFarland suspension 1:10 in sterile broth or saline to obtain a concentration of $10^{7} \mathrm{CFU} / \mathrm{ml}$, the adjusted suspensions for final inoculation should be used within $15 \mathrm{~min}$ of preparation. One McFarland standard (equivalent to $1.5 \times 10^{8} \mathrm{CFU} / \mathrm{ml}$ ) is used for fungal strains. These systems were then incubated at $37{ }^{\circ} \mathrm{C}$ for $24 \mathrm{~h}$ and $25{ }^{\circ} \mathrm{C}$ for $48 \mathrm{~h}$ for bacteria and yeasts, respectively. Controls lacking the oil were also included. Visual inspection of the developed turbidity of the microbial growth was carried out and MIC of the oil was determined. Turbidity due to the oil emulsion was obvious only at $\geq 5.0 \% \mathrm{v} / \mathrm{v}$. Average of 3 results was recorded.

\section{Agar-well diffusion method}

Fifty $\mathrm{ml}$ portions of molten sterile TSA or SDA maintained at $50{ }^{\circ} \mathrm{C}$ were inoculated, each with $100 \mu \mathrm{l}$ of properly diluted inoculum and mixed well. Inoculated medium was poured into sterile petri dish (ca.15 cm id.) and allowed to solidify. Wells, each of $6 \mathrm{~mm}$ diameters were removed leaving empty wells. These were $3 / 4$ filled with the OV EO or $1 \% \mathrm{v} / \mathrm{v}$ OV EO emulsion. The plates were allowed to stand at room temperature for $2 \mathrm{~h}$ and then incubated at $37^{\circ} \mathrm{C}$ for $18 \mathrm{~h}$ and at $25^{\circ} \mathrm{C}$ for $48 \mathrm{~h}$ in case of bacteria and yeast, respectively. The resultant inhibition zones were measured and the average values deduced (Balouiri et al. 2016). Average of 10 readings was recorded. Ampicillin, Ciprofloxacin and Amphotericin B were used as standard antimicrobial agents.

\section{Radiant giant colony method}

In case of $A$. niger, the radiant giant colony technique was used instead of the viable count technique because fungal spores were partially sensitive to the oil. SDA-oil plates containing $0-10 \% \mathrm{v} / \mathrm{v}$ of $\mathrm{OV}$ oil emulsion were prepared as described under "Agar dilution method". Ten microliter volume of the prepared $A$. niger spore suspension were transferred onto the centers of the oil plates, allowed to stand at room temperature for $30 \mathrm{~min}$ and then incubated at $25{ }^{\circ} \mathrm{C}$ for 5 days. The diameters of the 
developed radiating giant colonies of the fungus were accurately measured (Daferera et al. 2000).

\section{Calculation of colony count reduction}

The count of each colony/plate containing specified oil concentration was divided by that of the control lacking the oil and multiplied by 100 to obtain percent colony count reduction vs. oil concentration. The obtained values were plotted against the corresponding log OV EO concentration (Fekrazad et al. 2014).

\section{Biocidal activity of OV EO \\ Viable count technique}

Each reaction mixture was prepared by mixing $4.9 \mathrm{ml}$ aliquots of the OV EO emulsion having specified concentration with $100 \mu \mathrm{l}$ of the microbial inoculum under test. The mixture was vortexed and incubated at room temperature for specified time. It was then vortexed and $0.5 \mathrm{ml}$ volumes were withdrawn and decimally diluted with saline. The numbers of surviving cells were determined by transferring $20 \mu \mathrm{l}$ portions of each dilution onto the surface of over dried TSA or SDA plates and incubated at $37{ }^{\circ} \mathrm{C}$ for $48 \mathrm{~h}$ or at $25^{\circ} \mathrm{C}$ for $2-5$ days for the two media, respectively. The developed colonies were counted and average number of cells was calculated as $\mathrm{CFU} / \mathrm{ml}$. Control systems lacking the oil were also included.

\section{Effect of OV EO concentration}

The same procedure was followed except that the contact time was fixed at $5 \mathrm{~min}$ and oil concentration varied between 0 and $10 \% \mathrm{v} / \mathrm{v}$.

\section{Dynamics of the biocidal activity of OVEO}

The same procedure was followed except that the number of surviving cells was determined after 5 min- $6 \mathrm{~h}$ exposure of the test organism to $1 \% \mathrm{v} / \mathrm{v}$ OV EO. All figures were developed using GraphPad Prism ${ }^{\circledR}$ v. 5 software.

\section{Results}

\section{Chemical profile of OV essential oil}

Hydro-distillation of $O$. vulgare aerial parts yielded $0.85 \pm 0.05 \% \mathrm{v} / \mathrm{v}$ pale yellow EO. GC/MS of OV EO allowed the identification of 32 compounds representing 99.94\% of the oil (Table 1). Oxygenated monoterpenes predominated other classes of identified components; accounting for $75.41 \%$ of the oil (Fig. 1). This is attributed to the presence of the two major identified compounds in this class. These were terpinen-4-ol (38.35\%) and transsabinene hydrate (10.06\%) (Fig. 2). Other major identified constituents included $\alpha$-terpineol (7.32\%), $\alpha$-terpinene (4.51\%), cis-sabinene hydrate $(4.27 \%)$ and 4-terpinyl acetate $(4.13 \%)$.

\section{Antimicrobial studies}

Effect of emulsifiers on the antimicrobial activity of OV EO Immiscibility of essential oils with the aqueous culture media creates a methodological problem due to hindrance of proper diffusion. Accordingly, stable o/w emulsions of OV EO were prepared using Tween 20 and Cremphore El. Antimicrobial activity of the prepared oil emulsions was assessed using viable count technique. Results shown in Table 2 reveal that the use of these emulsifiers did not significantly affect the biocidal activity of OV EO Tween 20 was chosen for the experiments due to its relatively lower cost.

\section{Biostatic activity of OV EO}

Results of agar and broth dilution methods against the tested organisms are shown in Table 3. MIC values of agar dilution method revel that OV EO emulsion had the best activity against $S$. aureus, $\mathrm{Br}$. bronchiseptica and all the tested fungi with an MIC $2.36 \mathrm{mg} / \mathrm{ml}$. The least activity was observed against Ps. aeruginosa with an $\mathrm{MIC}>9.44 \mathrm{mg} / \mathrm{ml}$. Broth dilution method showed better results especially against Gram positive bacteria. The most sensitive organism was $S$. aureus with an MIC $1.18 \mathrm{mg} / \mathrm{ml}$, while the least sensitive one was also Ps. aeruginosa with an MIC $>18.88 \mathrm{mg} / \mathrm{ml}$. Agar diffusion method showed that the highest activity was observed against Br. bronchiseptica, Sac. cerevisiae, B. subtilis and $S$. epidermidis with inhibition zones $38 \pm 1.5,29.5 \pm 0.8$, $26.9 \pm 0.9$ and $26.9 \pm 1.1 \mathrm{~mm}$, respectively. Ps. aeruginosa was the least sensitive organism with inhibition zone $9.3 \pm 0.4 \mathrm{~mm}$.

\section{Biocidal activity of OV EO}

Biocidal activity of OV EO emulsion was studied using viable count technique against four selected organisms; $S$. aureus, E. coli. C. albicans and A. niger. Figure 3 shows the relationship between $\mathrm{OV}$ oil concentration and biocidal activity against the four selected organisms. Three of the resultant curves were linear over the entire oil concentration range $(0.05-5.0 \% \mathrm{v} / \mathrm{v})$ tested. The curve of $S$. aureus was bilinear having a much steeper part at oil concentration $\leq 1 \% \mathrm{v} / \mathrm{v}$. The curves of the four tested organisms displayed different slopes; that of $A$. niger was the most responsive while that of $C$. albicans was the least. OV oil emulsion concentrations causing 50\% and $75 \%$ microbial growth inhibition were calculated from the dose response curve obtained in Fig. 3 (Table 4).

\section{Dynamics of the biocidal activity of OV EO}

The dynamics of OV EO emulsion biocidal activity against 10 microorganisms are presented in Figs. 4, 5, and 
Table 1 Identified constituents in OV EO using GC/MS analysis

\begin{tabular}{|c|c|c|c|c|c|c|}
\hline No. & $\mathbf{R t}$ & Compound & $\mathrm{KI}^{\mathrm{a}}$ (calculated) & KI (reported) & $\begin{array}{l}\text { Rel. abundance } \\
\text { (\%) }\end{array}$ & $\begin{array}{l}\text { Methods } \\
\text { of identification }\end{array}$ \\
\hline & & Monoterpene hydrocarbons & & & 21.91 & \\
\hline 1 & 6.065 & a-Thujene & 918 & 916 & 0.90 & $\mathrm{Kl}, \mathrm{MS}$ \\
\hline 2 & 6.240 & a-Pinene & 931 & 929 & 0.22 & $\mathrm{Kl}, \mathrm{MS}, \mathrm{AT}$ \\
\hline 3 & 7.330 & Sabinene & 991 & 995 & 2.37 & $\mathrm{Kl}, \mathrm{MS}$ \\
\hline 4 & 7.412 & $\beta$-Pinene & 989 & 986 & 0.17 & $\mathrm{KI}, \mathrm{MS}, \mathrm{AT}$ \\
\hline 5 & 7.823 & $\beta$-Myrcene & 1005 & 1008 & 0.67 & $\mathrm{Kl}, \mathrm{MS}$ \\
\hline 6 & 8.194 & a-Phellandrene & 1012 & 1015 & 0.22 & $\mathrm{Kl}, \mathrm{MS}$ \\
\hline 7 & 8.541 & a-Terpinene & 1025 & 1026 & 4.51 & $\mathrm{Kl}, \mathrm{MS}$ \\
\hline 8 & 8.804 & p-Cymene & 1036 & 1039 & 3.15 & $\mathrm{Kl}, \mathrm{MS}, \mathrm{AT}$ \\
\hline 9 & 8.900 & $\beta$-Phellandrene & 1027 & 1031 & 1.66 & $\mathrm{Kl}, \mathrm{MS}$ \\
\hline \multirow[t]{2}{*}{10} & 9.784 & ү-Terpinene & 1052 & 1053 & 8.04 & $\mathrm{Kl}, \mathrm{MS}, \mathrm{AT}$ \\
\hline & & Oxygenated monoterpenes & & & 75.41 & \\
\hline 11 & 9.040 & 1,8-Cineol & 1026 & 1025 & 0.57 & $\mathrm{KI}, \mathrm{MS}, \mathrm{AT}$ \\
\hline 12 & 10.145 & cis-Sabinene hydrate & 1063 & 1065 & 4.27 & $\mathrm{Kl}, \mathrm{MS}, \mathrm{AT}$ \\
\hline 13 & 10.663 & a-Terpinolene & 1079 & 1082 & 1.68 & $\mathrm{KI}, \mathrm{MS}$ \\
\hline 14 & 11.087 & trans-Sabinene hydrate & 1089 & 1083 & 10.06 & $\mathrm{Kl}, \mathrm{MS}, \mathrm{AT}$ \\
\hline 15 & 11.757 & Camphor & 1152 & 1158 & 2.99 & $\mathrm{KI}, \mathrm{MS}, \mathrm{AT}$ \\
\hline 16 & 12.323 & Linalool & 1257 & 1255 & 2.06 & $\mathrm{Kl}, \mathrm{MS}, \mathrm{AT}$ \\
\hline 17 & 13.409 & Terpinen-4-ol & 1259 & 1265 & 38.35 & $\mathrm{Kl}, \mathrm{MS}, \mathrm{AT}$ \\
\hline 18 & 13.839 & a-Terpineol & 1296 & 1301 & 7.32 & $\mathrm{KI}, \mathrm{MS}, \mathrm{AT}$ \\
\hline 19 & 13.955 & Estragole & 1312 & 1311 & 1.06 & $\mathrm{Kl}, \mathrm{MS}$ \\
\hline 20 & 14.340 & cis-Piperitol & 1351 & 1358 & 1.03 & $\mathrm{Kl}, \mathrm{MS}$ \\
\hline 21 & 15.567 & Linalyl acetate & 1389 & 1398 & 1.37 & $\mathrm{Kl}, \mathrm{MS}$ \\
\hline 22 & 16.854 & 4-Terpinyl acetate & 1415 & 1419 & 4.13 & $\mathrm{Kl}, \mathrm{MS}$ \\
\hline 23 & 16.939 & Carvone & 1435 & 1436 & 0.26 & $\mathrm{KI}, \mathrm{MS}, \mathrm{AT}$ \\
\hline 24 & 17.188 & p-Cymen-8-ol & 1441 & 1438 & 0.20 & $\mathrm{Kl}, \mathrm{MS}$ \\
\hline \multirow[t]{2}{*}{25} & 19.256 & Eugenol & 1485 & 1498 & 0.06 & $\mathrm{Kl}, \mathrm{MS}, \mathrm{AT}$ \\
\hline & & Sesquiterpene hydrocarbons & & & 1.36 & \\
\hline 26 & 13.748 & a-Humulene & 1278 & 1282 & 0.17 & $\mathrm{Kl}, \mathrm{MS}$ \\
\hline 27 & 17.793 & Bicycloelemene & 1578 & 1572 & 0.10 & $\mathrm{Kl}, \mathrm{MS}$ \\
\hline 28 & 18.195 & $\gamma$-Cadinene & 1625 & 1632 & 0.07 & $\mathrm{Kl}, \mathrm{MS}$ \\
\hline 29 & 20.018 & trans-Caryophyllene & 1412 & 1410 & 0.86 & $\mathrm{Kl}, \mathrm{MS}, \mathrm{AT}$ \\
\hline \multirow[t]{2}{*}{30} & 22.008 & Bicyclogermacrene & 1494 & 1489 & 0.16 & $\mathrm{Kl}, \mathrm{MS}$ \\
\hline & & Oxygenated sesquiterpenes & & & 1.26 & \\
\hline 31 & 24.080 & Spathulenol & 1577 & 1585 & 0.57 & $\mathrm{KI}, \mathrm{MS}, \mathrm{AT}$ \\
\hline \multirow[t]{3}{*}{32} & 24.182 & Caryophyllene oxide & 1570 & 1568 & 0.69 & $\mathrm{Kl}, \mathrm{MS}, \mathrm{AT}$ \\
\hline & & Total \% of identified compounds & & & 99.94 & \\
\hline & & Total number of identified compounds & & & 32.00 & \\
\hline
\end{tabular}

KI Kovat's index, MS mass spectral data from wiley libraries, AT comparison with authentic compound

${ }^{a} \mathrm{KI}$, Kovat's index determined on RTX-5MS capillary column

6. These figures relate the level of biocidal activity of $1 \%$ $\mathrm{v} / \mathrm{v}$ of OV EO emulsion vs. time of exposure of the test organisms.

Figure 4 shows the dynamics of the bactericidal activity of the oil against $3 \mathrm{Gram}$ negative bacteria. The response of both E. coli and Br. bronchiseptica was quite rapid; more than $99.999 \%$ of the exposed cells (ca $10^{7}$ CFU/ $\mathrm{ml})$ were killed within 5 min contact with the oil $(1 \% \mathrm{v} / \mathrm{v})$ and no re-growth was detected after that. In contrast, the response of Ps. aeruginosa was distinctly different, exhibiting bilinear response vs. time. The first part of dynamic response was relatively rapid leading to $3 \log$ reductions in the number of cells surviving the first $5 \mathrm{~min}$ of incubation. Thereafter, killing rate decreased markedly and, at 


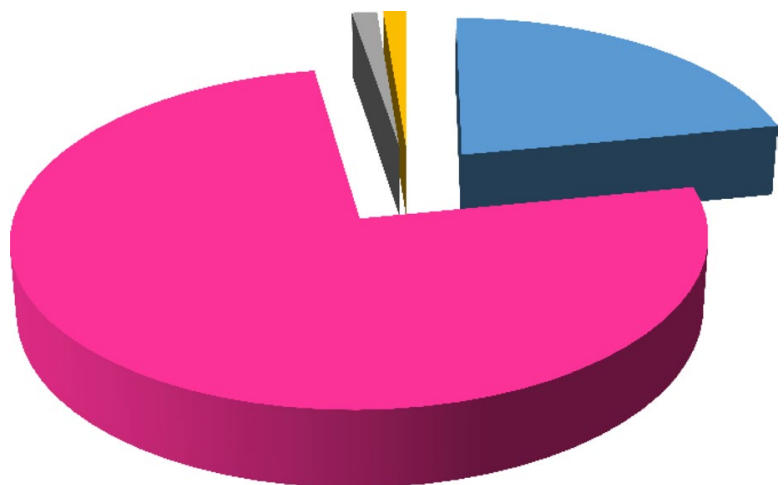

- Monoterpene hydrocarbons

- Oxygenated monoterpenes

- Sesquiterpene hydrocarbons

Oxygenated sesquiterpenes

Fig. 1 Percentage distribution of classes of constituents identified in OV EO

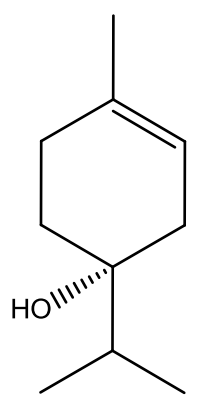

Terpinen-4-ol trans-sabinene hydrate the end of the experiment ( $6 \mathrm{~h})$, ca $10^{4} \mathrm{CFU} / \mathrm{ml}$ was still living.

Figure 5 shows the dynamics of biocidal of $1 \% \mathrm{v} / \mathrm{v}$ oil emulsion against $5 \mathrm{Gram}$ positive bacteria. Among these, $B$. subtilis spores were completely insensitive followed by $M$. lutea which displayed only small $(1 \mathrm{log})$ initial drop in the number of cells surviving after 30 min contact with the oil with no further drop. E. faecalis showed intermediate response for ca 2 logs. Reduction in viable count took place within $2 \mathrm{~h}$ contact with the oil and further insignificant reduction occurred during the remaining $4 \mathrm{~h}$ of incubation. A sigmoid curve was observed with $S$. aureus. It showed ca $4 \operatorname{logs}$ reduction in the number of survivor by the end of the first $2 \mathrm{~h}$ of contact with the oil followed by ca $1.5 \log$ further reductions by the last hour of inoculation $(6 \mathrm{~h})$. The dynamic of biocidal response of $S$. epidermidis was quite rapid showing more than $99.999 \%$ killing by the end of the first $2 \mathrm{~h}$ of contact with the oil and no further growth was noticed. When $B$. subtilis culture was exposed to $1 \% \mathrm{v} / \mathrm{v}$ of OV EO, ca. 5.5 $\log$ reduction in the inoculated cells $(7.5 \operatorname{logs})$ took place quite rapidly $(15 \mathrm{~min})$ and remained the same for the rest of the experiment $(6 \mathrm{~h})$. These survivors were found to be entirely spores; confirming the non-sporicidal activity of the OV EO.

The dynamics of the biocidal activity of $1 \% \mathrm{v} / \mathrm{v}$ OV EO emulsion against $C$. albicans and $S$. cerevisiae (yeast strains) are shown in Fig. 6. The latter strain was sensitive to the oil since practically all the exposed cells (ca.

Table 2 Effect of Tween 20 and Cremophor El on the antimicrobial activity of OV EO

\begin{tabular}{|c|c|c|c|c|}
\hline \multirow[t]{3}{*}{ System } & \multirow[t]{3}{*}{ Oil conc. (\%v/v) } & \multicolumn{3}{|c|}{ Test microorganism (ATCC no.) } \\
\hline & & S. aureus (6538) & E. coli (8729) & C. albicans (10231) \\
\hline & & \multicolumn{3}{|c|}{ Viable count, CFU/ml ${ }^{\mathrm{a}}$ (\%killing) } \\
\hline \multirow[t]{2}{*}{ Water $^{b}$} & 0 & $5.58 \times 10^{6}$ & $2.05 \times 10^{7}$ & $2.58 \times 10^{6}$ \\
\hline & 2 & $5.02 \times 10^{3}(99.902)$ & $<5.00 \times 10^{1}(>99.999)$ & $2.35 \times 10^{3}(99.909)$ \\
\hline \multirow[t]{2}{*}{ Tween 20, 1\% } & 0 & $5.26 \times 10^{6}$ & $9.50 \times 10^{6}$ & $5.25 \times 10^{5}$ \\
\hline & 2 & $1.18 \times 10^{5}(97.8)$ & $<5.00 \times 10^{1}(>99.999)$ & $1.35 \times 10^{4}(97.429)$ \\
\hline \multirow[t]{2}{*}{ Crempohor El, 1\% } & 0 & $5.25 \times 10^{6}$ & $9.55 \times 10^{6}$ & $5.25 \times 10^{5}$ \\
\hline & 2 & $2.00 \times 10^{5}(96.20)$ & $<5.00 \times 10^{1}(>99.999)$ & $8.30 \times 10^{3}(98.40)$ \\
\hline
\end{tabular}

\footnotetext{
${ }^{a}$ Average of three determinations carried out by surface viable method after 5 min at RT $\left(24^{\circ} \mathrm{C}\right)$

b The system was intermittently vortexed for $5 \mathrm{~min}$
} 
Table 3 Biostatic activity of OV EO

\begin{tabular}{|c|c|c|c|c|}
\hline \multirow[t]{3}{*}{ Test microorganism (ATCC no.) } & \multicolumn{4}{|c|}{ Method of assessment } \\
\hline & \multirow{2}{*}{$\begin{array}{l}\text { Agar dilution } \\
\text { MIC }(\mathrm{mg} / \mathrm{ml})^{\mathrm{a}}\end{array}$} & \multirow[t]{2}{*}{ Broth dilution } & \multicolumn{2}{|c|}{ Agar diffusion } \\
\hline & & & \multicolumn{2}{|c|}{ Inhibition zone, $\mathrm{mm}^{\mathbf{b}}$} \\
\hline \multicolumn{5}{|l|}{ Ampicillin } \\
\hline \multicolumn{5}{|l|}{ Gram positive organisms } \\
\hline B. subtilis (6633) & 2.36 & 2.36 & $26.9 \pm 0.9$ & $22 \pm 0.5$ \\
\hline E. faecalis (8043) & 9.44 & 2.36 & $13.6 \pm 0.3$ & $18 \pm 0.7$ \\
\hline M. lutea (9341) & 4.72 & 2.36 & $20.6 \pm 0.7$ & $15 \pm 0.9$ \\
\hline S. aureus (6538) & 2.36 & 1.18 & $20.5 \pm 0.6$ & $12 \pm 0.4$ \\
\hline S. epidermidis (12228) & 9.44 & 2.36 & $26.9 \pm 1.1$ & $21 \pm 0.8$ \\
\hline \multicolumn{5}{|l|}{ Gram negative organisms } \\
\hline Br. bronchiseptica (4617) & 2.36 & 2.36 & $38 \pm 1.5$ & $23 \pm 0.7$ \\
\hline E. coli $(8729)$ & 4.72 & 4.72 & $12.9 \pm 0.8$ & $10 \pm 0.8$ \\
\hline Ps. aeruginosa (9027) & $>9.44$ & $>18.88$ & $9.3 \pm 0.4$ & $15 \pm 0.4$ \\
\hline \multicolumn{5}{|l|}{ Fungi } \\
\hline C. albicans (10231) & 2.36 & 2.36 & $16.1 \pm 0.9$ & $15 \pm 0.3$ \\
\hline S. cerevisiae (2601) & 2.36 & 2.36 & $29.5 \pm 0.8$ & $23 \pm 0.5$ \\
\hline A. niger (16404) & 2.36 & - & - & $16 \pm 0.8$ \\
\hline
\end{tabular}

a Minimum Inhibitory concentration, average of three determinations

b Average of 10 readings

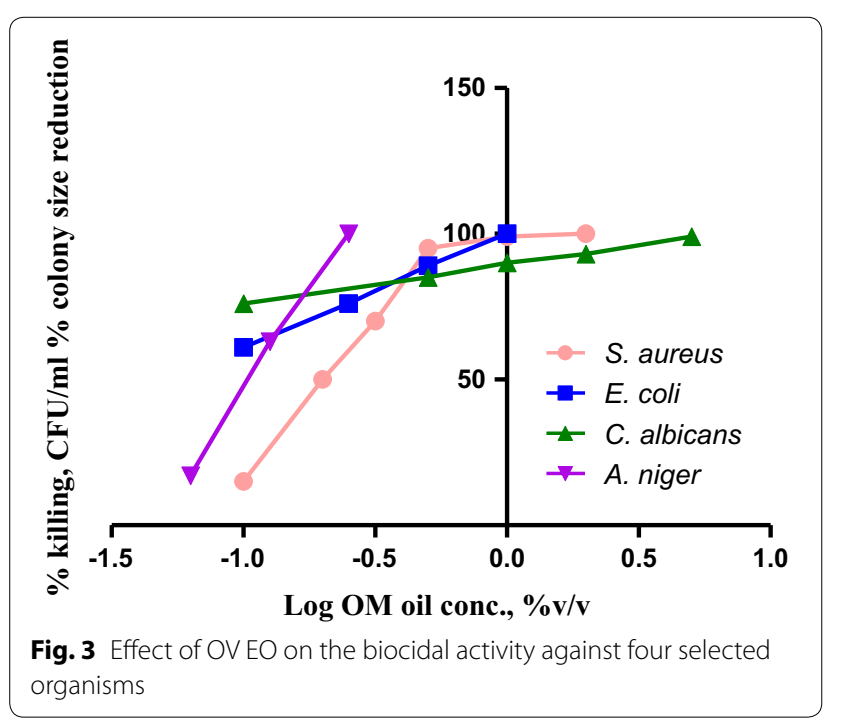

$10^{7} \mathrm{CFU} / \mathrm{ml}$ ) were killed during the first $30 \mathrm{~min}$ of contact. On the other hand, C. albicans cells exhibited much slower dynamics and, at the end of the experiment $(6 \mathrm{~h})$, out of 7.5 logs of exposed cells, ca. 4.5 logs were still surviving.

\section{Discussion}

The essential oil composition of Origanum genus has been extensively studied, and has shown a wide variation between its different species. The variation in composition may even be present within the same species collected during different seasons or from different geographical areas. In the present study, GC/MS analysis of the hydro-distilled OV EO allowed the identification of 32 compounds representing $99.94 \%$ of the oil. The major identified compound was the oxygenated monoterpene; terpinen-4-ol. Terpinen-4-ol was also the major identified constituent of the OV EO grown in India, Israel and Venezuela (Govindarajan et al. 2016; Ramos et al. 2011; Ravid et al. 1987; Vera and Chane-Ming 1999). It is also a major constituent in the oil of other Origanum species like O. ramonese, O. scabrum and O. microphyllum (Aligiannis et al. 2001; Danin et al. 1997). Results of the biostatic studies on OV EO using agar and broth dilution methods showed that $S$. aureus was the most sensitive organism to OV EO emulsion., with an MIC $0.125 \% \mathrm{v} / \mathrm{v}$. Other studies also report a high sensitivity of $S$. aureus to OV EO with an MIC ranging 0.31-10 $\mu \mathrm{g} / \mathrm{ml}$ (Honório et al. 2015; Pesavento et al. 2015; Tavares et al. 2015). Agar diffusion method showed that the highest activity was observed against $\mathrm{Br}$. bronchiseptica, Sac. cerevisiae, B. subtilis and S. epidermidis with inhibition zones $38 \pm 1.5,29.5 \pm 0.8,26.9 \pm 0.9$ and $26.9 \pm 1.1 \mathrm{~mm}$, respectively. It should be also noted that the Gram negative 
Table 4 Concentrations of OV EO causing 50\% and 75\% microbial growth inhibition

\begin{tabular}{lll}
\hline Test microorganism & $\begin{array}{l}\text { Oil conc. causing 50\% } \\
\text { microbial growth } \\
\text { inhibition }(\% \mathbf{v} / \mathbf{v})\end{array}$ & $\begin{array}{l}\text { Oil conc. causing 75\% } \\
\text { microbial growth } \\
\text { inhibition }(\% \mathbf{v} / \mathbf{v})\end{array}$ \\
\hline E. coli & 0.08 & 0.21 \\
S. aureus & 0.17 & 0.34 \\
A. niger & 0.11 & 0.15 \\
C. albicans & 0.07 & 0.09 \\
\hline
\end{tabular}

Concentrations are calculated from dose-response curve (Fig. 1)

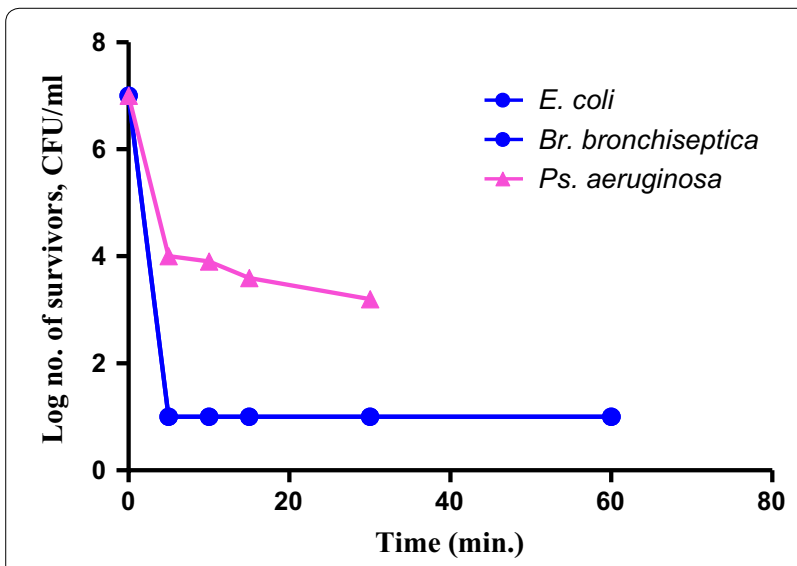

Fig. 4 Biocidal dynamics of OV EO (1\% v/v) against three Gram negative bacteria

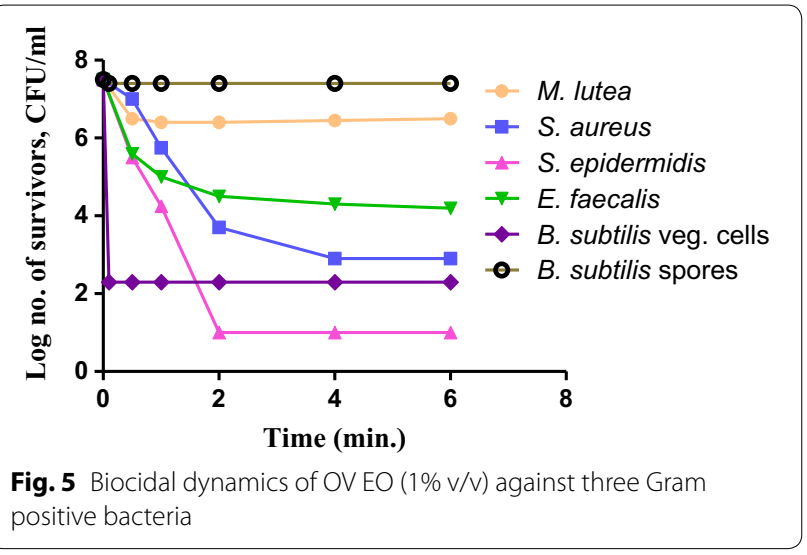

Pseudomonas aeruginosa was the least sensitive organism, as shown by the results obtained by all the used tests, while $A$. niger was completely insensitive as shown by the broth dilution and agar diffusion methods. On the other side, study of the biocidal activity of OV EO emulsion using viable count technique showed that $75 \%$ of $C$. albicans colonies died at a concentration of $0.09 \% \mathrm{v} / \mathrm{v}$ of the

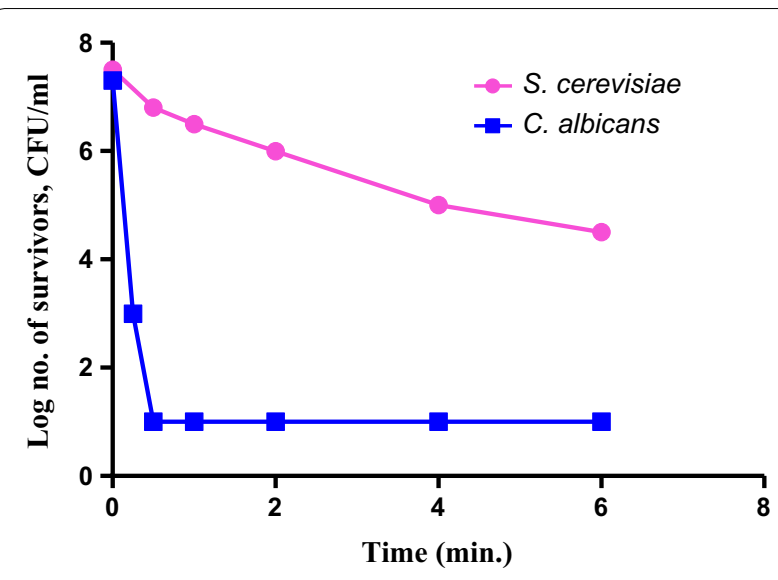

Fig. 6 Biocidal dynamics of OV EO (1\% v/v) against two yeast strains

oil emulsion in only $5 \mathrm{~min}$. This is supported by several studies that show a high activity of OV EO against different Candida species, especially vaginal and oral Candida (Bhat et al. 2018; Cleff et al. 2010). Studying the dynamics of $1 \% \mathrm{v} / \mathrm{v}$ OV EO emulsion over a period of $6 \mathrm{~h}$ revealed that E. coli, B. subtilis, S. epidermidis and S. cerevisiae had the fastest response, while all other organisms had more or less intermediate response except for $B$. subtilis spores which were completely insensitive to the oil emulsion. This markedly strong antimicrobial activity may be attributed to the presence of the alcohol terpinene-4-ol in the EO. This compound has proven a strong antimicrobial activity against several organisms like $B$. subtilis, Bacteroides fragilis, Candida spp., Clostridium perfringens, E. faecalis, E. coli, Lactobacillus acidophilus, Moraxella catarrhalis, Mycobacterium smegmatis, Ps. aeruginosa, Serratia marcescens and S. aureus (Carson and Riley 1995; Hammer et al. 2012; Mondello et al. 2006). Terpinen-4-ol is also the major compound present in tea tree oil which is known for its broad spectrum antimicrobial properties (Carson et al. 2006; Lee et al. 2013; Sharifi$\mathrm{Rad}$ et al. 2017). The suggested mechanism of action of terpinen-4-ol may be due to compromising of the cytoplasmic membrane (Carson et al. 2002), or penetration of organelle membrane inducing deformation, damage and eventually microbial cell death (Li et al. 2016).

In conclusion, results obtained in this study showed that OV EO possesses strong antibacterial and antifungal activities, especially against $S$. aureus and Br. bronchiseptica which may be attributed mainly to the presence of terpinen-4-ol in its essential oil composition.

\section{Abbreviations}

B. subtilis: Bacillus subtilis; E. faecalis: Enterococcus faecalis; M. Iutea: Micrococcus Iutea; S. aureus: Staphylococcus aureus; S. epidermidis: Staphylococcus epidermidis; Br. bronchiseptica: Brodetella bronchiseptica; E. coli: Escherichia coli; Ps. aeruginosa: Pseudomonas aeruginosa; C. albicans: Candida albicans; S. cerevisiae: 
Saccharomyces cerevisiae; A. niger: Aspergillus niger; OV: Origanum vulgare; $O$. vulgare: Origanum vulgare; GC/MS: gas chromatography/mass spectrometry; EO: essential oil; MAPs: medicinal and aromatic plants; ATCC: American Type Culture Collection; MIC: minimum inhibitory concentration; TSA: trypticase soy agar; SDA: Sabouraud Dextrose Agar; id: internal diameter; v/v: volume/ volume; h: hour; min.: minutes.

\section{Authors' contributions}

Conception and design of the study was proposed by OS and SF. Acquisition of data was carried out by NK and SF. Interpretation of data, statistical analysis and drafting of the article was carried out by NK and SF. Revising the article critically was carried out by OS. Final approval of the version to be submitted was carried out by NK, SF and OS. All authors read and approved the final manuscript.

\section{Author details}

1 Faculty of Allied Medical Sciences, Pharos University in Alexandria, Alexandria 21311, Egypt. ${ }^{2}$ Faculty of Pharmaceutical Sciences and Pharmaceutical Industries, Future University in Egypt, Cairo 11835, Egypt.

\section{Acknowledgements}

Not applicable.

\section{Competing interests}

The authors declare that they have no competing interests.

\section{Availability of data and materials}

The used strains are available upon request. All obtained data have been included into the manuscript.

\section{Consent for publication}

Not applicable.

Ethics approval and consent to participate

Not applicable.

\section{Funding}

Not applicable.

\section{Publisher's Note}

Springer Nature remains neutral with regard to jurisdictional claims in published maps and institutional affiliations.

Received: 10 March 2019 Accepted: 18 March 2019

Published online: 26 March 2019

\section{References}

Adams RP (2007) Identification of essential oil components by gas chromatography/quadrupole mass spectroscopy, vol 1, 4th edn. Allured Publishing Corporation, lllinois

Aligiannis N, Kalpoutzakis E, Mitaku S, Chinou IB (2001) Composition and antimicrobial activity of the essential oils of two Origanum species. J Agric Food Chem 49(9):4168-4170

Arranz E, Jaime L, López de las Hazas MC, Reglero G, Santoyo S (2015) Supercritical fluid extraction as an alternative process to obtain essential oils with anti-inflammatory properties from marjoram and sweet basil. Ind Crops Prod 67:121-129. https://doi.org/10.1016/j.indcrop.2015.01.012

Balouiri M, Sadiki M, Ibnsouda S (2016) Methods for in vitro evaluating antimicrobial activity: a review. J Pharm Anal 6(2):71-79. https://doi. org/10.1016/j.jpha.2015.11.005

Bhalla Y, Gupta VK, Jaitak V (2013) Anticancer activity of essential oils: a review. J Sci Food Agric 93(15):3643-3653. https://doi.org/10.1002/jsfa.6267

Bhat V, Sharma S, Shetty V, Shastry C, Rao C, Shenoy S, Saha S, Balaji S (2018) Characterization of herbal antifungal agent, Origanum vulgare against Oral Candida spp. isolated from patients with Candida-associated denture stomatitis: an in vitro study. Contemp Clin Dent 9(Suppl 1):S3-S10. https://doi.org/10.4103/ccd.ccd_537_17
Carneiro de Barros J, Lúcia da Conceição M, Gomes Neto N, Vieira da Costa A, Siqueira J, Basílio I, Leite de Souza E (2009) Interference of Origanum vulgare L. essential oil on the growth and some physiological characteristics of Staphylococcus aureus strains isolated from foods. LWT-Food Sci Technol 42(6):1139-1143. https://doi.org/10.1016/j.lwt.2009.01.010

Carson CF, Riley TV (1995) Antimicrobial activity of the major components of the essential oil of Melaleuca alternifolia. J Appl Bacteriol 78(3):264-299

Carson CF, Mee B, Riley TV (2002) Mechanism of action of Melaleuca alternifolia (tea tree) oil on Staphylococcus aureus determined by time-kill, lysis, leakage, and salt tolerance assays and electron microscopy. Antimicrob Agents Chemother 46(6):1914-1920. https://doi.org/10.1128/ AAC.46.6.1914-1920.2002

Carson CF, Hammer KA, Riley TV (2006) Melaleuca alternifolia (Tea Tree) oil: a review of antimicrobial and other medicinal properties. Clin Microbiol Rev 19(1):50-62. https://doi.org/10.1128/CMR.19.1.50-62.2006

Chaves-Lopez C, Martin-Sanchez AM, Fuentes-Zaragoza E, Viuda-Martos M, Fernandez-Lopez J, Sendra E, Sayas E, Angel Perez Alvarez J (2012) Role of Oregano (Origanum vulgare) essential oil as a surface fungus inhibitor on fermented sausages: evaluation of its effect on microbial and physicochemical characteristics. J Food Prot 75(1):104-111. https://doi. org/10.4315/0362-028x.jfp-11-184

Cleff M, Meinerz A, Xavier M, Schuch L, Araújo Meireles M, Alves Rodrigues M, de Mello J (2010) In vitro activity of Origanum vulgare essential oil against Candida species. Braz J Microbiol 41(1):116-123. https://doi.org/10.1590/ S1517-838220100001000018

CLSI (2012) Performance standards for antimicrobial disk susceptibility tests, approved standard, 7th ed. In: CLSI document M02-A11 edn. Clinical and Laboratory Standards Institute, 950 West Valley Road, Suite 2500, Wayne, Pennsylvania 19087, USA

Coccimiglio J, Alipour M, Jiang Z, Gottardo C, Suntres Z (2016) Antioxidant, antibacterial, and cytotoxic activities of the ethanolic Origanum vulgare extract and its major constituents. Oxid Med Cell Longev 2016:1404505. https://doi.org/10.1155/2016/1404505

Daferera DJ, Ziogas BN, Polissiou MG (2000) GC-MS analysis of essential oils from some Greek aromatic plants and their fungitoxicity on Penicillium digitatum. J Agric Food Chem 48:2576-2581

Danin A, Ravid U, Umano K, Shibamoto T (1997) Essential oil composition of Origanum ramonense Danin leaves from Israel. J Essent Oil Res 9(4):411417. https://doi.org/10.1080/10412905.1997.9700741

de Barros JC, da Conceicao ML, Neto NJ, da Costa AC, de Souza EL (2012) Combination of Origanum vulgare L. essential oil and lactic acid to inhibit Staphylococcus aureus in meat broth and meat model. Braz J Microbiol 43(3):1120-1127. https://doi.org/10.1590/s1517-838220120003000039

Dhifi W, Bellili S, Jazi S, Bahloul N, MnifW (2016) Essential oils' chemical characterization and investigation of some biological activities: a critical review. Medicines 3(4):25

Didry N, Dubreuil L, Pinkas M (1993) Antibacterial activity of thymol, carvacrol and cinnamaldehyde alone or in combination. Pharmazie 48(4):301-304

Elshafie H, Armentano M, Carmosino M, Bufo S, De Feo V, Camele I (2017) Cytotoxic activity of Origanum vulgare L. on hepatocellular carcinoma cell line HepG2 and evaluation of its biological activity. Molecules 22(9):1435. https://doi.org/10.3390/molecules22091435

Fekrazad R, Zare H, Morsali P (2014) The effect of antimicrobial photodynamic therapy with radachlorin ${ }^{\circledR}$ on Staphylococcus aureus and Escherichia coli: an in vitro study. J Lasers Med Sci 5(2):82-85

Fleisher A, Sneer N (1982) Oregano spices and Origanum chemotypes. J Sci Food Agric 33(5):441-446. https://doi.org/10.1002/jsfa.2740330508

Gong HY, Liu WH, Lv GY, Zhou X (2014) Analysis of essential oils of Origanum vulgare from six production areas of China and Pakistan. Rev Bras Farmacogn 24(1):25-32. https://doi.org/10.1590/0102-695X2014241434

Govindarajan M, Rajeswary M, Hoti SL, Benelli G (2016) Larvicidal potential of carvacrol and terpinen-4-ol from the essential oil of Origanum vulgare (Lamiaceae) against Anopheles stephensi, Anopheles subpictus, Culex quinquefasciatus and Culex tritaeniorhynchus (Diptera: Culicidae). Res Vet Sci 104:77-82. https://doi.org/10.1016/j.rvsc.2015.11.011

Griffin SG, Markham JL, Leach DN (2000) An agar dilution method for the determination of the minimum inhibitory concentration of essential oils. J Essent Oil Res 12(2):249-255. https://doi.org/10.1080/10412 905.2000.9699509

Hammer K, Carson CF, Riley TV (2012) Effects of Melaleuca alternifolia (Tea Tree) essential oil and the major monoterpene component terpinen-4-ol on 
the development of single- and multistep antibiotic resistance and antimicrobial susceptibility. Antimicrob Agents Chemother 56(2):909. https:// doi.org/10.1128/AAC.05741-11

Herman A, Herman A, Domagalska B, Młynarczyk A (2013) Essential oils and herbal extracts as antimicrobial agents in cosmetic emulsion. Indian J Microbiol 53(2):232-237. https://doi.org/10.1007/s12088-012-0329-0

Hernández-Hernández E, Regalado-González C, Vázquez-Landaverde P, Guerrero-Legarreta I, García-Almendárez B (2014) Microencapsulation, chemical characterization, and antimicrobial activity of Mexican (Lippia graveolens H.B.K.) and European (Origanum vulgare L.) oregano essential oils. Sci World J 2014:12. https://doi.org/10.1155/2014/641814

Honório V, Bezerra J, Souza G, Carvalho R, Gomes-Neto N, Figueiredo R, Melo J, Souza E, Magnani M (2015) Inhibition of Staphylococcus aureus cocktail using the synergies of oregano and rosemary essential oils or carvacrol and 1,8-cineole. Front Microbiol 6:1223. https://doi.org/10.3389/fmicb .2015.01223

Kacaniova M, Terentjeva M, Vukovic N, Puchalski C, Roychoudhury S, Kunova S, Kluga A, Tokar M, Kluz M, Ivanisova E (2017) The antioxidant and antimicrobial activity of essential oils against Pseudomonas spp. isolated from fish. Saudi Pharm J 25(8):1108-1116. https://doi.org/10.1016/j. jsps.2017.07.005

Khan M, Khan S, Khan N, Mahmood A, Al-Kedhairy A, Alkhathlan H (2018) The composition of the essential oil and aqueous distillate of Origanum vulgare L. growing in Saudi Arabia and evaluation of their antibacterial activity. Arab J Chem 11(8):1189-1200. https://doi.org/10.1016/j.arabj c.2018.02.008

Kokkini S, Karousou R, Hanlidou E (2003) HERBS|Herbs of the Labiatae. In: Caballero B (ed) Encyclopedia of food sciences and nutrition, 2nd edn. Academic Press, Oxford, pp 3082-3090

Krishnakumar V, Potty SN (2012) Handbook of herbs and spices, 2nd edn. Woodhead Publishing, Sawton, pp 336-365

Lee C, Chen L, Chen L, Chang T, Huang C, Huang M, Wang C (2013) Correlations of the components of tea tree oil with its antibacterial effects and skin irritation. J Food Drug Anal 21(2):169-176. https://doi.org/10.1016/j. jfda.2013.05.007

Leyva-López N, Gutiérrez-Grijalva E, Vazquez-Olivo G, Heredia J (2017) Essential oils of oregano: biological activity beyond their antimicrobial properties. Molecules 22(6):989. https://doi.org/10.3390/molecules22060989

Li WR, Li HL, Shi QS, Sun TL, Xie XB, Song B, Huang XM (2016) The dynamics and mechanism of the antimicrobial activity of tea tree oil against bacteria and fungi. Appl Microbiol Biotechnol 100(20):8865-8875. https://doi. org/10.1007/s00253-016-7692-4

Magi G, Marini E, Facinelli B (2015) Antimicrobial activity of essential oils and carvacrol, and synergy of carvacrol and erythromycin, against clinical, erythromycin-resistant group A Streptococci. Front Microbiol 6:165. https ://doi.org/10.3389/fmicb.2015.00165

Milos M, Mastelic J, Jerkovic I (2000) Chemical composition and antioxidant effect of glycosidically bound volatile compounds from oregano (Origanum vulgare L. ssp. hirtum). Food Chem 71(1):79-83. https://doi. org/10.1016/S0308-8146(00)00144-8

Moghaddam M, Mehdizadeh L (2017) Chapter 13-chemistry of essential oils and factors influencing their constituents. In: Grumezescu A, Holban A (eds) Soft chemistry and food fermentation. Academic Press, New York, pp 379-419
Mondello F, De Bernardis F, Girolamo A, Cassone A, Salvatore G (2006) In vivo activity of terpinen-4-ol, the main bioactive component of Melaleuca alternifolia Cheel (tea tree) oil against azole-susceptible and -resistant human pathogenic Candida species. BMC Infect Dis 6:158. https://doi. org/10.1186/1471-2334-6-158

Morshedloo MR, Craker LE, Salami A, Nazeri V, Sang H, Maggi F (2017) Effect of prolonged water stress on essential oil content, compositions and gene expression patterns of mono- and sesquiterpene synthesis in two oregano (Origanum vulgare L.) subspecies. Plant Physiol Biochem 111:119-128. https://doi.org/10.1016/j.plaphy.2016.11.023

Morshedloo M, Mumivand H, Craker L, Maggi F (2018) Chemical composition and antioxidant activity of essential oils in Origanum vulgare subsp. gracile at different phenological stages and plant parts. J Food Process Preserv 42(2):13516. https://doi.org/10.1111/jfpp.13516

Pesavento G, Calonico C, Bilia AR, Barnabei M, Calesini F, Addona R, Mencarelli L, Carmagnini L, Di Martino MC, Lo Nostro A (2015) Antibacterial activity of Oregano, Rosmarinus and Thymus essential oils against Staphylococcus aureus and Listeria monocytogenes in beef meatballs. Food Control 54:188-199. https://doi.org/10.1016/j.foodcont.2015.01.045

Pradebon Brondani L, da Silva Alves, Neto T, Antonio Freitag R, Guerra Lund R (2018) Evaluation of anti-enzyme properties of Origanum vulgare essential oil against oral Candida albicans. J Mycol Med 28(1):94-100. https:// doi.org/10.1016/j.mycmed.2017.12.001

Prakash B, Singh P, Kedia A, Dubey N (2012) Assessment of some essential oils as food preservatives based on antifungal, antiaflatoxin, antioxidant activities and in vivo efficacy in food system. Food Res Int 49(1):201-208. https://doi.org/10.1016/j.foodres.2012.08.020

Ramos S, Rojas L, Lucena M, Meccia G, Usubillaga A (2011) Chemical composition and antibacterial activity of Origanum majorana L. essential oil from the venezuelan andes. J Essent Oil Res 23(5):45-49. https://doi. org/10.1080/10412905.2011.9700481

Ravid U, Bassat M, Putievsky E, Ikan R, Weinstein V (1987) Determination of the enantiomeric composition of (+)-terpinen-4-ol from sweet marjoram Origanum majorana L. using a chiral lanthanide shift reagent. Flavour Fragr J 2(1):17-19. https://doi.org/10.1002/ff.2730020104

Sharifi-Rad J, Salehi B, Varoni EM, Sharopov F, Yousaf Z, Ayatollahi SA, Kobarfard F, Sharifi-Rad M, Afdjei MH, Sharifi-Rad M, Iriti M (2017) Plants of the Melaleuca genus as antimicrobial agents: from farm to pharmacy. Phytother Res 31(10):1475-1494. https://doi.org/10.1002/ptr.5880

Sharifi-Rad M, Varoni EM, Iriti M, Martorell M, Setzer WN, Del Mar Contreras M, Salehi B, Soltani-Nejad A, Rajabi S, Tajbakhsh M, Sharifi-Rad J (2018) Carvacrol and human health: a comprehensive review. Phytother Res 32(9):1675-1687. https://doi.org/10.1002/ptr.6103

Soliman M, Abdo Nassan M, Ismail T (2016) Origanum Majoranum extract modulates gene expression, hepatic and renal changes in a rat model of type 2 diabetes. Iran J Pharm Res 15(Suppl):45-54

Tavares AG, Monte DF, Albuquerque Ados R, Sampaio FC, Magnani M, Siqueira Junior JP, Souza EL (2015) Habituation of enterotoxigenic Staphylococcus aureus to Origanum vulgare L. essential oil does not induce directtolerance and cross-tolerance to salts and organic acids. Braz J Microbiol 46(3):835-840. https://doi.org/10.1590/s1517-838246320140355

Vera RR, Chane-Ming J (1999) Chemical composition of the essential oil of marjoram (Origanum majorana L) from Reunion Island. Food Chem 66(2):143-145. https://doi.org/10.1016/S0308-8146(98)00018-1 